\title{
PRÁTICAS NO ENSINO DE LÍNGUAS ADICIONAIS PARA CRIANÇAS: UM LEVANTAMENTO EXPLORATÓRIO
}

\author{
Helena Vitalina Selbach ${ }^{1}$ \\ Natália Lopes Robaina ${ }^{2}$ \\ Daniel Henrique Hoffmann ${ }^{3}$
}

Resumo: Os contextos de ensino de línguas adicionais vêm se diversificando na contemporaneidade
e, dentre eles, está o crescente ensino de língua inglesa (LI) para crianças (CIRINO; DENARDI,
2019). Neste trabalho, apresentamos um levantamento bibliográfico exploratório de relatos de
pesquisas sobre práticas no ensino de línguas adicionais para crianças nos contextos da Educaçáo
Infantil e/ou no Ensino Fundamental I. O enfoque recai sobre trabalhos empíricos recentes que
reportam experiências no ensino e na formação de professores de línguas para crianças. De natureza

1 Professora da Universidade Federal de Santa Maria (UFSM). Doutora em Letras (Estudos Linguísticos) pela Universidade Federal de Santa Maria (2018), Mestre em Linguística Aplicada pela Universidade Federal do Rio Grande do Sul (2014), Bacharel em Letras (Português-Inglês) pela mesma universidade (2000) e Licenciada em Letras (Português-Inglês) pela Universidade Franciscana (2017). Atualmente, é colaboradora dos projetos de pesquisa 1) Laboratório virtual de Ensino e Aprendizagem de Línguas Online (LabEon): pesquisa, ensino e extensão da UFSM e 2) FELICE/ CNPq - Formacão de professores e ensino de línguas para crianças da Universidade Estadual de Londrina. Colabora com os projetos de extensão 1) LabEOn: Ensino de Línguas a distância via Extensão Universitária da UFSM e 2) TEIA - Teachers of English in Action - PROJETO INTEGRADO DE FORMAÇÁO (INICIAL E CONTINUADA) DE PROFESSORES DE INGLÊS da Universidade Estadual de Londrina. Integra a comissão do Teste de Suficiência em Leitura em Língua Estrangeira (TESLLE) da UFSM, colaborando como elaboradora da área de inglês. Suas áreas de interesse, inscritas na Linguística Aplicada, referemse a práticas de letramento, ensino e aprendizagem de línguas adicionais e educação inicial e continuada de professores de línguas.

2 Atualmente, cursando graduação em Letras - Licenciatura - Habilitação: Inglês e Literaturas da Língua Inglesa pela Universidade Federal de Santa Maria. Em 2017, atuou como monitora bolsista do projeto Línguas no Campus (LINC), vinculado ao Laboratório de Pesquisa e Ensino de Leitura e Redação pela UFSM. Em 2018 participou do projeto de Extensão intitulado Projeto Integrado de Extensão do DLEM - Centro de Línguas e Literatura De 2018 a 2019, participou como bolsista do Programa Institucional de Bolsa de Iniciação à Docência. No ano de 2020, foi integrante do projeto Letramentos em língua inglesa com comunidades de prática da educação infantil e dos anos iniciais. Atua na área de Linguística Aplicada.

3 Acadêmico do Curso de Licenciatura em Letras Inglês e Literaturas da Língua Inglesa pela Universidade Federal de Santa Maria. Auxiliar Administrativo no Projeto Línguas no Campus (LINC), vinculado ao Laboratório de Pesquisa e Ensino de Leitura e Redação (2020). Participou como Monitor no projeto LINC-Línguas no Campus pela Universidade Federal de Santa Maria (2019). Participou do Projeto de Ensino de Alemão como língua estrangeira pela Universidade Federal de Santa Maria (2019). 
qualitativa, este trabalho inscreve-se no âmbito da Linguística Aplicada na medida em que se preocupa com questôes de uso da linguagem (CAVALCANTI, 1986) relativas a açóes afirmativas e a práticas de sala de aula. Os resultados apontam a predominância da LI em relação às demais línguas, bem como uma variação em termos de temáticas de ensino e açóes de educação de professores, objetivos de pesquisa, resultados e/ou impactos das pesquisas para as comunidades escolares investigadas.

Palavras-chave: Ensino. Experiências. Educação de professores.

\title{
PRACTICES IN TEACHING ADDITIONAL LANGUAGES TO CHILDREN: AN EXPLORATORY REVIEW
}

\begin{abstract}
The contexts of additional language teaching have been diversifying, and among those contexts, there is the growing teaching of the English language (EL) for children (CIRINO; DENARDI, 2019). We present an exploratory bibliographic review of research reports on practices in teaching additional languages to children in the contexts of Early Childhood Education and/ or Primary School. The focus is on recent empirical works that report experiences on teaching and education language teachers for children. This work is of qualitative nature and is inscribed within the scope of Applied Linguistics, insofar as it is concerned with issues of language use (CAVALCANTI, 1986) related to affirmative actions and classroom practices. The results indicate the predominance of EL in relation to the other languages, as well as a variety of teaching themes and teacher education actions, research objectives, results and/or impacts of the research for the investigated school communities.
\end{abstract}

Keywords: Teaching. Experiences. Teacher education.

\section{CONSIDERAÇÓES INICIAIS}

Os contextos de ensino de língua adicional (LA) ${ }^{4}$, em especial o de língua inglesa (LI), vêm se diversificando na contemporaneidade, e, dentre eles, está o crescente ensino de LI para crianças (LIC) (TANACA, 2017; CIRINO; DENARDI, 2019). Características desse ensino incluem, além da promoção do desenvolvimento linguístico da criança, o estímulo ao seu crescimento físico, sociocultural, intelectual e emocional, ou seja, ao seu desenvolvimento integral (ROCHA, 2007).

Neste trabalho, apresentamos um levantamento bibliográfico exploratório de relatos de pesquisas recentes voltados a práticas no ensino de línguas adicionais para crianças (LAC) nos contextos da Educação Infantil (EI) e/ou no Ensino Fundamental I (EFI). O enfoque recai sobre trabalhos empíricos e propositivos que reportam e discutem experiências de sala de aula em termos de impactos positivos e desafios enfrentados no ensino ou na formação de professores de línguas para crianças. Distanciamo-nos, assim, de relatos que se detêm em apontar a má qualidade do

4 Optamos pelo termo Línguas adicionais, conforme Schlatter e Garcez (2012, p. 37), por entendermos que ele se acresce a outras línguas do repertório do educando brasileiro e integra os "recursos necessários para a cidadania contemporânea". Utilizaremos o termo Língua estrangeira sempre que fizermos referência a autores que usam tal denominação. 
ensino de línguas adicionais e reforçar o discurso da impossibilidade de se aprender uma LA na escola (SCHLATTER, 2009). Este trabalho é de natureza qualitativa, uma vez que busca explorar uma gama de dimensóes do mundo social, como as experiências dos participantes e os significados que produzem (MASON, 2002) a partir dos relatos de pesquisa do corpus. Inscreve-se no âmbito da Linguística Aplicada na medida em que se preocupa com questóes de uso da linguagem (CAVALCANTI, 1986) em açóes afirmativas e em práticas de sala de aula no contexto da EI e/ou EFI. Essas açóes orientam-se para intervençóes benéficas na realidade a partir da construção de conhecimento "que seja responsivo à vida social" (MOITA LOPES, 2006, p. 97).

Na próxima seção, tratamos do ensino de LAC e da formação de professores para esse contexto. Em seguida, descrevemos a metodologia empregada para, entâo, apresentarmos e discutirmos os dados em termos de temáticas abordadas, perfis dos participantes, objetivo(s) de pesquisa, tipo de estudo e resultado(s) e/ou impacto(s) das pesquisas relatadas. Por fim, apresentamos as considerações finais.

\section{O ENSINO DE LÍNGUAS ADICIONAIS PARA CRIANÇAS E A FORMAÇÃO DE PROFESSORES}

O contexto de ensino de LAC no Brasil é uma realidade em franca expansão (ROCHA, 2007; FORTE, 2010; TONELLI; CRISTÓVÃO, 2010; CIRINO; DENARDI, 2019). Embora a prática de ensino de LAC venha crescendo nas mais diferentes esferas, redes e modalidades de ensino, verifica-se uma carência de registro cuidadoso de dados quanto à historicidade e oferta:

[...] não há dados precisos com relação à história da oferta de LEC [língua estrangeira para crianças] nas escolas brasileiras, do mesmo modo que náo há dados oficiais nem especulativos acerca da quantidade de municípios e escolas brasileiras que já oferecem aulas de língua estrangeira a alunos desde o início da vida escolar. Sabe-se, contudo, que a oferta ainda se dá de maneira heterogênea nas diversas escolas brasileiras e que é consenso entre os pesquisadores da área que ela se encontra em fase de expansão [...], o que se nota pela presença da LE [língua estrangeira] nos anos iniciais em todas as esferas escolares, existindo, inclusive, escolas de idiomas específicas para este tipo de público (COLOMBO; CONSOLO, 2016, p. 56).

Aliada à ausência de dados oficiais ${ }^{5}$ sobre o status do ensino de LAC no Brasil e à crescente oferta e demanda por esse ensino, verifica-se uma lacuna na formação de professores de LAC para atuação nos contextos da EI e do EFI. Essa lacuna devese à formação oferecida pelos cursos de Letras e de Pedagogia; os cursos de Letras formam professores para atuar no Ensino Fundamental II (EFII) e no Ensino Médio

5 Há iniciativas de grupos de pesquisa, como o grupo FELICE (Formação de professores e ensino de línguas para crianças), voltadas ao mapeamento de teses e dissertaçóes sobre bilinguismo, ensino de línguas estrangeiras para crianças, avaliação no ensino de línguas estrangeiras para crianças e formação de professores para esse contexto. Disponível em: https://feliceuel.wordpress. com/mapeamento/. Acesso em: 01 fev. 2021. 
(EM), enquanto os alunos da EI e do EFI são atendidos por profissionais formados pelos cursos de Pedagogia que não contemplam o ensino de LA, pois se dedicam às disciplinas do currículo geral (FERNANDEZ; RINALDI, 2009 apud CIRINO; DENARDI, 2019). Temos, de um lado, um crescimento na oferta de LI na EI e no EFI e, de outro, a ausência de formaçáo inicial de professores $^{6}$ para atuar nesses contextos que demandam enfoque teórico-metodológico específico: "a universidade oferta novos profissionais para atuação com o ensino de língua inglesa, porém sem as características exigidas pelo mercado de trabalho da educação infantil" (CIRINO; DENARDI, 2019, p. 221). Essa atuação profissional envolve diversas facetas, tais como materiais didáticos, abordagens, métodos e avaliação de ensino (TONELLI; CRISTOVÃO, 2010). As autoras defendem que o professor LIC seja capaz de

\begin{abstract}
[...] dominar a língua a ser ensinada/aprendida; considerar os contextos em que atua para poder transformar sua prática docente; exercer sua profissão bem fundamentado em bases teóricas, sem desconsiderar que prática e teoria estáo intimamente imbricadas; dominar métodos e abordagens que sejam coerentes com as necessidades dos educandos; agir de forma crítica e reflexiva nos contextos em que se encontra; entre outros aspectos.

Entendendo que os cursos de Letras devam se adaptar às novas realidades e necessidades no desempenho do ensino de línguas é que defendemos a formação (inicial e continuada) de profissionais que possam também atuar em contextos de ensino de LIC. Nessa perspectiva, defendemos a formaçáo global e plural do profissional de LIC e, para tal, acreditamos na necessidade da inserção de programas para a formação desse professor [...] (TONELLI; CRISTOVÃO, 2010, p. 68).
\end{abstract}

O ensino de LAC, a partir de uma perspectiva sócio e intercultural, tem o potencial de contribuir para o desenvolvimento da criança em termos de conhecimento de si e do mundo, de compreensão e valorização das diferenças, de ação no mundo plurilíngue e pluricultural, assegurando, à criança, igualdade de oportunidades que incluem o direito ao ensino de uma LA (ROCHA, 2007). Apesar de não ser obrigatório, o fato de esse ensino integrar a matriz curricular de escolas privadas desde o EI até o EM "nos impede de abordar sua ausência nos ciclos iniciais do Ensino Fundamental Público, sem tocar na questão da exclusão social (Boneti, 1997) vivenciada pelos alunos das classes menos favorecidas" (ROCHA, 2007, p. 280). Rocha (2007) ainda chama a atenção para a correlação entre a não obrigatoriedade do ensino de língua estrangeira no EFI e a ausência de parâmetros para esse ensino, o que compromete o processo de ensino e aprendizagem de línguas que vem sendo elaborado em várias escolas públicas brasileiras apesar da não obrigatoriedade. Nosso pressuposto alinha-se ao da autora, ao afirmar que

6 Essa asserção deve-se à ausência, de forma homogênea, de disciplinas obrigatórias específicas para o ensino de LAC nas grades curriculares dos cursos de Letras brasileiros, como apontam Tonelli e Cristovão (2010, p. 67): "Apesar de haver diretrizes curriculares para os cursos de licenciatura (incluindo o curso de Letras) e referenciais e parâmetros (Brasil, 1996, 1997, 1998, 2006) para vários níveis, o ensino de línguas estrangeiras nas séries iniciais ou na educação infantil não está especificamente contemplado". 
[...] independentemente das limitaçóes típicas do ensino de LE em escolas regulares, sejam elas públicas ou particulares, defendemos a existência do mesmo desde o início da aprendizagem formal e a necessidade que o ensino em questão seja alvo de intensas investigaçóes científicas, a fim de que possamos garantir o papel formador da LE nesse contexto e preservar o direito do cidadáo de aprender línguas na escola, efetivamente (ROCHA, 2007, p. 281).

Tendo em vista o número reduzido de investigaçôes - e de divulgação das pesquisas realizadas nesse contexto - "com pertinência explícita ao ensino da LI nas séries iniciais do Ensino Fundamental, o que demonstra a necessidade de pesquisas e publicaçóes que abordem, especificamente, essa temática" (SCAGLION; ARAÚJO; GIROTO, 2019, p. 373), buscamos contribuir para a investigação em LA sobre práticas de ensino recentes de LAC na EI e também no EFI a partir deste levantamento. Apresentamos, na próxima seção, o percurso metodológico deste levantamento exploratório.

\section{METODOLOGIA}

Para o processo de busca de artigos, utilizamos, como plataforma de base de dados, o Google Acadêmico, através da ferramenta "Pesquisa Avançada", por meio de orações. As oraçôes pesquisadas foram formadas pela combinação dos termos e expressóes: professores, línguas estrangeiras ${ }^{7}$, educação infantil, ensino fundamental, aprendizagem, infantil e crianças, tendo em vista o enfoque deste trabalho. Inicialmente, utilizamos o campo do formulário da Pesquisa Avançada "Com no mínimo uma das palavras", em que foram inseridas as principais palavras-chave da temática, que poderiam estar presentes em qualquer lugar do artigo publicado no período entre 2015 e 2020. Essa pesquisa inicial produziu um total de 441.000 resultados, e, para que obtivéssemos uma busca mais específica, foi necessário utilizarmos outras ferramentas da Pesquisa Avançada. Dessa forma, utilizamos a expressão "Práticas no ensino de línguas estrangeiras para crianças" que sintetizava a temática da busca a ser inserida no campo do formulário da Pesquisa Avançada "Com a frase exata". A expressáo gerou um total de 63 resultados, que foram analisados de acordo com o objetivo desta pesquisa e com os critérios estabelecidos.

7 Optamos por linguas estrangeiras em razão do termo ser "mais antigo e familiar" (JORDÃO, 2014, p. 15). Segundo a autora (p. 29-30), "No Brasil se percebe que o termo língua adicional tem um espaço maior do que fora do país, embora ainda sendo usado apenas timidamente [...] para situaçóes de aprendizagem de inglês em contextos plurilíngues e em contextos em que os aprendizes compartilham uma primeira língua diferente do inglês. Com base neste breve levantamento de títulos no Brasil e no exterior, a diferenciação mais comum nos dois contextos parece tomar o ambiente de contato com a língua como principal referência, de modo que, quando este ambiente é de imigrantes aprendendo a língua do país onde moram, usa-se geralmente "língua adicional", enquanto em ambientes como os das escolas brasileiras, nos quais a sociedade nacional não usa inglês para comunicação interna, a maioria dos pesquisadores vem usando o termo "estrangeira"”. 
Para integrarem o corpus deste trabalho, os relatos de pesquisa deveriam ser recentes, ou seja, ter sua publicação datada entre os anos de 2015 e 2020, e tratar de açóes afirmativas e práticas de sala de aula relacionadas ao ensino de LAC e formação de professores para esse contexto. Dos 63 resultados, nove artigos foram selecionados ${ }^{8}$.

Os nove artigos do corpus foram, entáo, analisados em termos de:

1) temática;

2) perfis dos participantes e contexto de atuação dos professores;

3) língua (LA ensinada/aprendida);

4) objetivo(s) de pesquisa;

5) tipo de estudo (abordagem e instrumento(s) de pesquisa);

6) resultado(s) e/ou impacto(s) da pesquisa relatada.

O Quadro 1 compila os artigos que compóem o corpus deste trabalho, identificando-os com uma numeração, seguida da identificação da LA tratada em cada relato. A identificaçáo \#1ING, por exemplo, corresponde ao artigo de número "um" que trata do ensino de LI.

Quadro 1 - Dados do corpus

\begin{tabular}{|c|l|}
\hline $\begin{array}{c}\text { IDENTIFICAÇÃO } \\
\text { DO ARTIGO }\end{array}$ & \multicolumn{1}{c|}{ REFERÊNCIA } \\
\hline \multirow{3}{*}{ \#1ING } & $\begin{array}{l}\text { BETTONI, Melissa; CAMPOS, Fernando Rosseto Gallego. A pronúncia } \\
\text { do ensino de inglês para crianças: Crenças e práticas do professor. } \\
\text { REVELLI-Revista de Educaçáo, Linguagem e Literatura, v. 9, n. 4, p. } \\
1-20,2018 .\end{array}$ \\
\hline \multirow{3}{*}{ \#2ING } & $\begin{array}{l}\text { TEIXEIRA, Valéria Fuchs; MARZARI, Gabriela Quatrin. O ensino da } \\
\text { língua inglesa na Educaçá Infantil: “Estamos sendo preparados para } \\
\text { isso?”. Disciplinarum Scientia. Série: Ciências Humanas, v. 17, n. 2, p. } \\
\text { 155-177, 2016. }\end{array}$ \\
\hline \multirow{3}{*}{ \#3ING } & $\begin{array}{l}\text { BEZERRA, Isabel Cristina Rangel Moraes; DOS SANTOS, Monike } \\
\text { Ribeiro. Língua Inglesa para crianças e um projeto de iniciação à } \\
\text { docência: Formação inicial exploratória. Revista Aproximando, v. 4, n. } \\
\text { 5, 2018. }\end{array}$ \\
\hline \multirow{3}{*}{ \#4ING } & $\begin{array}{l}\text { TONELLI, Juliana Reichert Assunção; BUENO, Bruna Alessandra } \\
\text { Graef. O parecer descritivo na avaliação do ensino e da aprendizagem } \\
\text { de crianças aprendendo inglês como língua estrangeira. PERcursos } \\
\text { Linguísticos, v. 9, n. 23, p. 110-129, 2019. }\end{array}$ \\
\hline
\end{tabular}

8 Os demais relatos foram excluídos em virtude de: 1) não seguirem os critérios estabelecidos (não tratarem de práticas de sala de aula, por exemplo, serem artigos exclusivamente teóricos ou que tratassem exclusivamente de análises de material didático sem a participaçáo de atores sociais como professores e alunos), 2) estarem duplicados, e/ou 3) náo serem artigos publicados em revistas. 


\begin{tabular}{|c|l|}
\hline $\begin{array}{c}\text { IDENTIFICAÇÃO } \\
\text { DO ARTIGO }\end{array}$ & \multicolumn{1}{c|}{ REFERÊNCIA } \\
\hline \#5ESP & $\begin{array}{l}\text { DE ALBUQUERQUE, Ana Paula Cavalcante; QUEVEDO- } \\
\text { CAMARGO, Gladys. O projeto Petit e Pequeños e o livro didático } \\
\text { adotado: Uma experiência de ensino de espanhol para crianças. Revista } \\
\text { Iberoamericana de Educación, v. 75, n. 1, p. 9-24, 2017. }\end{array}$ \\
\hline \#6ING & $\begin{array}{l}\text { LIMA, Ana Paula; DE SOUZA NETO, Samuel. A formação em serviço } \\
\text { e o desenvolvimento profissional de professores de inglês para crianças. } \\
\text { PERcursos Linguísticos, v. 9, n. 23, p. 130-147, 2019. }\end{array}$ \\
\hline \#7ING & $\begin{array}{l}\text { GALVÂO, Ana Sara Manhabusque; FURLAN, Claudia Jotto Kawachi. } \\
\text { Ensino-aprendizagem de inglês na Educação Infantil: Consideraçóes } \\
\text { sobre multiletramentos e formação docente. PERcursos Linguísticos, v. } \\
\text { 9, n. 23, p. 148-165, 2019. }\end{array}$ \\
\hline K8FRA & $\begin{array}{l}\text { KUYUMJIAN, Naraina de Melo Martins. O ensino do francês como } \\
\text { língua estrangeira para crianças: Uma sequência didática. Entrelinhas, v. } \\
\text { 9, n. 1, p. 74-90, 2015. }\end{array}$ \\
\hline TONING & $\begin{array}{l}\text { TONELLI, Juliana Reichert Assunção; DE SOUZA PÁDUA, Lívia. A } \\
\text { sequência didática como uma proposta de instrumento de avaliaçáo de } \\
\text { aprendizagem de inglês para crianças. Cadernos do IL, n. 52, p. 508- } \\
\text { 530, 2016. }\end{array}$ \\
\hline
\end{tabular}

Fonte: Elaboração própria

Dos artigos que compóem o corpus, há três artigos publicados em 2019, dois entre os anos de 2016 e 2018, um artigo publicado em 2015 e outro em 2017. Com relação à LA tratada nos relatos, a maioria dos artigos (sete, identificados como \#1ING, \#2ING, \#3ING, \#4ING, \#6ING, \#7ING, \#9ING) aborda práticas de ensino de aprendizagem de LI. Há ainda um artigo sobre ensino de língua espanhola (\#5ESP) e outro sobre língua francesa (\#8FRA). Na próxima seção, tratamos da análise dos dados gerados a partir desse corpus.

\section{ANÁLISE E DISCUSSÃO DOS RESULTADOS}

Nesta seção, apresentamos e discutimos os resultados em termos de: 1) temáticas abordadas nos relatos de pesquisa, 2) perfis dos participantes, 3) objetivos das pesquisas, 4) tipos de estudo e, por fim, 5) resultados/impactos. Essas categorizaçóes correspondem à cada uma das subseções.

\section{TEMÁTICAS ABORDADAS}

Duas grandes temáticas foram identificadas a partir de nossa busca. A primeira diz respeito à Formação de professores de LI para crianças, que é tratada em cinco do total de nove artigos analisados, e a segunda refere-se ao Ensino das línguas inglesa, francesa e espanhola para crianças, correspondente a seis artigos. Essas duas temáticas são disponibilizadas no Quadro 2, que apresenta, além das temáticas e suas subdivisões, exemplares dessas temáticas e a indicação das mesmas nos artigos. 
Quadro 2 - Temáticas

\begin{tabular}{|c|c|l|}
\hline \multicolumn{2}{|l|}{ TEMÁTICAS } & EXEMPLOS \\
\hline \multirow{4}{*}{$\begin{array}{c}\text { Formação de } \\
\text { professores }\end{array}$} & Formação inicial & $\begin{array}{l}\text { Ensino de pronúncia (\#1ING) } \\
\text { Matrizes curriculares (\#2ING) } \\
\text { Prática exploratória (\#3ING) } \\
\text { Multiletramentos na EI (\#7ING) }\end{array}$ \\
\cline { 2 - 3 } & $\begin{array}{c}\text { Formação continuada/ } \\
\text { em serviço }\end{array}$ & $\begin{array}{l}\text { LI para crianças na perspectiva do desenvolvimento } \\
\text { profissional docente (\#6ING) }\end{array}$ \\
\hline \multirow{3}{*}{ Ensino } & Práticas de ensino & $\begin{array}{l}\text { Projeto de iniciação à docência (\#3ING) } \\
\text { Material didático em projeto de ensino (\#5ESP) } \\
\text { Sequência didática (\#8FRA) }\end{array}$ \\
\cline { 2 - 3 } & Avaliação do ensino & $\begin{array}{l}\text { Pronúncia (\#1ING) } \\
\text { Parecer descritivo (\#4ING) } \\
\text { Sequência didática (\#9ING) }\end{array}$ \\
\hline
\end{tabular}

Fonte: Elaboração própria

A temática Formação de professores refere-se exclusivamente à formação em LI e se subdivide em formaçáo inicial e formaçáo continuada e/ou em serviço. Já a segunda, Ensino, está subdividida em práticas e avaliação do ensino.

A formação inicial compreende a maioria (quatro) dos artigos, estando a formação continuada e/ou em serviço representada com um artigo. Os temas investigados na temática formação inicial são variados e perpassam ensino de pronúncia, matrizes curriculares, prática exploratória e multiletramentos. $\mathrm{O}$ ensino de pronúncia (\#1ING) é tratado em termos de sua importância para a educação de crianças de 2 a 7 anos de idade e de 8 a 12 anos, da relevância do estudo da pronúncia e da área da Fonologia para a formação do professor de LIC. O estudo busca, ainda, entender os impactos da intervenção realizada na disciplina de Fonética e Fonologia nas crenças e práticas dos professores de LI em formaçáo inicial em relação à pronúncia.

Matrizes curriculares (\#2ING) é a temática explorada na formação inicial de professores de LI por meio da investigação sobre sua (não) adequação ao ensino eficiente de LI para crianças de 0 a 6 anos. $\mathrm{O}$ estudo retoma pesquisas sobre formação de professores e ensino da língua estrangeira na EI para compreender como esses temas são abordados nas matrizes curriculares dos cursos de Letras; apresenta também dados de entrevistas com professoras da EI sobre como se sentem em relação ao preparo, na formação inicial, para atuarem na EI e sobre as dificuldades enfrentadas em seus contextos profissionais.

Os princípios da Prática Exploratória (\#3ING) embasam, a partir de um trabalho colaborativo e reflexivo, a construção de uma proposta metodológica para o ensino de LI, no qual o planejamento das aulas e das atividades de ensinoaprendizagem é sensível ao contexto sócio-histórico-cultural dos aprendizes. As autoras constroem materiais didáticos para auxiliar no desenvolvimento do 
processo de ensino aprendizagem, com um foco mais crítico e reflexivo a partir do pressuposto de que a língua tem um papel formador de cidadãos e também se configura como ação social.

A temática da Pedagogia dos Multiletramentos na EI (\#7ING) é mobilizada a partir da investigação dos desafios do ensino de LI nesse contexto. A análise enfoca o planejamento de aulas de professores voluntários de LI, em período de formação inicial, em um Projeto de Extensão que ocorre em um Centro de Educaçáo Infantil, vinculado à uma universidade federal.

A formação continuada, por sua vez, é tratada a partir da perspectiva do desenvolvimento profissional docente (\#6ING) por meio de recorte de uma pesquisa de doutorado que trata da formaçáo de professores de LIC. A análise dos dados aponta para a viabilidade de momentos formativos (por exemplo, reunióes semanais com a pesquisadora sobre as turmas dos quartos e quintos anos do EFI municipal e encontros formativos na Secretaria da Educação do Município no Horário de Trabalho Pedagógico Coletivo) que buscam favorecer o desenvolvimento profissional docente, principalmente em funçáo da possibilidade da socialização entre os docentes.

A temática Ensino enfoca práticas de ensino das línguas inglesa, espanhola e francesa e avaliação do ensino em LI. As práticas de ensino das línguas espanhola e francesa tratam, respectivamente, de produção de material didático e de sequência didática (SD). Na construção de um projeto de ensino (\#5ESP), foram analisados acertos e desacertos no trabalho realizado em uma escola pública, por uma equipe de professoras de espanhol, uma coordenadora e crianças do quinto ano, a partir do trabalho embasado no livro didático (LD) Ventanita al español 1. Já a construçáo de uma SD (\#8FRA), desenvolvida para crianças de quatro e sete anos de idade, com o tema "Os animais", teve a competência oral, a manipulaçáo e o contexto como noçóes norteadoras para o desenvolvimento das aulas. As atividades foram elaboradas com os alunos, construídas de acordo com as necessidades, possibilidades e vontade dos participantes, do ambiente de trabalho e dos objetivos estabelecidos. O ensino da LI é reportado a partir de um Projeto de iniciaçáo à docência (\#3ING), desenvolvido no EFI, que segue os princípios da prática exploratória no qual o grupo, composto pela professora orientadora e bolsistas, busca construir uma atitude crítico reflexiva sobre a prática docente. As bolsistas são encorajadas a analisar criticamente as atividades propostas e as experiências em sala de aula, e os alunos a criar questóes sobre seus contextos, estimulando o seu desenvolvimento crítico através de práticas de letramento em LI. Para tanto, foram promovidas discussões e reflexôes por meio de puzzles e questóes instigantes sobre a qualidade da vida dentro e no entorno da sala de aula/escola.

A avaliação do ensino é abordada por meio de avaliação de pronúncia, de parecer descritivo (PD) e de SD. A avaliação de pronúncia (\#1ING) foi realizada por meio de questionários, respondidos por professores de LIC, na disciplina de Fonética e Fonologia da LI de um curso de pós-graduação em Ensino de LI em um Instituto Federal. O questionário inicial continha perguntas que investigavam 
crenças sobre a pronúncia dos professores em formaçáo continuada, sobre o ensino da pronúncia, bem como práticas em sala de aula. O segundo questionário buscou identificar possível(is) mudança(s) de crenças dos professores e o que acreditavam ser a reação dos seus alunos diante da pronúncia. O PD (\#4ING) é utilizado na avaliação do ensino de LI a partir da proposta de uma grade de critérios avaliativos que compóem um instrumento orientador voltado a avaliar, registrar e reportar, nos PDs, o desenvolvimento e a aprendizagem de alunos do primeiro ano do EFI de uma escola privada nas aulas de LI. Há ainda uma terceira possibilidade de avaliação por meio de SD (\#9ING), que foi desenvolvida e dinamizada com uma turma de quinto ano do EF. A SD foi produzida tendo como base o livro de histórias The Little Cloud, e teve como finalidade verificar se os alunos estavam alcançando os objetivos esperados.

\section{PERFIS DOS PARTICIPANTES}

Analisamos os perfis dos participantes das pesquisas e seu contexto de atuação, quais sejam, professores em formaçáo inicial ou continuada que atuam com alunos da EI ou do EFI da rede pública ou privada e os respectivos níveis/anos cursados. Os Gráficos 1 e 2 apresentam, respectivamente, esses dados.

Gráfico 1 - Contexto

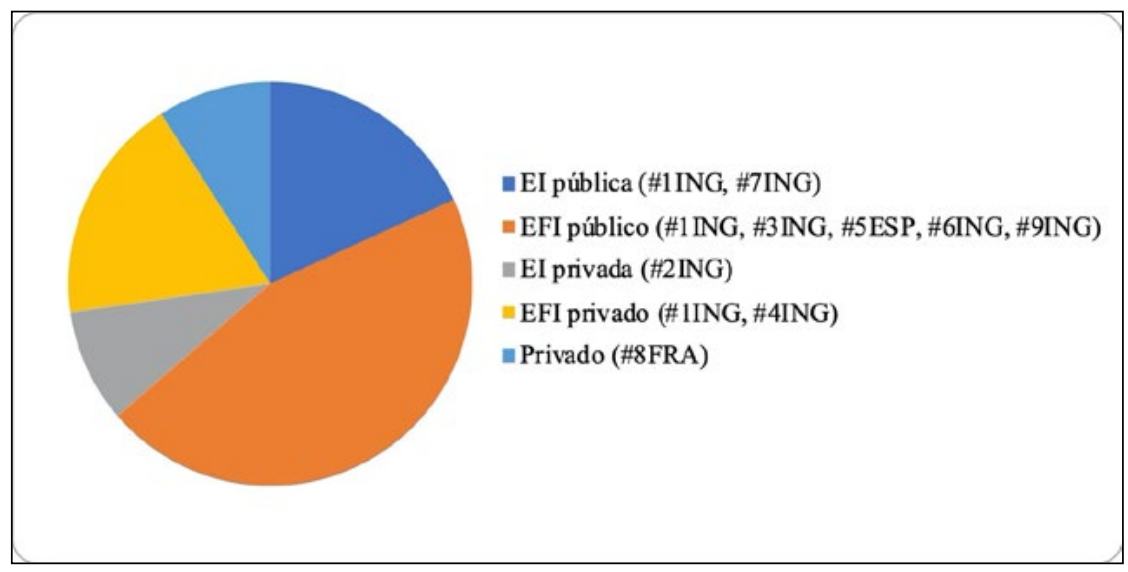

Fonte: Elaboração própria 


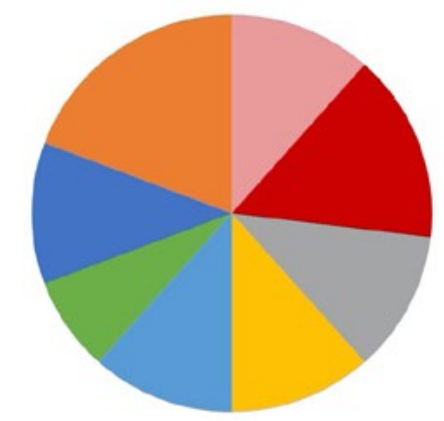

= Matemal (\#1ING, \#2ING, \#7ING)

- Pré 1 (\#1ING, \#2ING, \#7ING, \#8FRA)

॥ Pré 2 (\#1ING, \#2ING, \#7ING)

= Ano 1 ( \#1ING, \#3ING, \#4ING)

= Ano 2 (\#1 ING, \#3ING, \#8FRA)

- Ano 3 (\#1 ING, \#3ING)

- Ano 4 ( \#1 ING, \#3ING, \#6ING)

= Ano 5 (\#IING, \#3ING, \#5ESP, \#6ING, \#8FRA)

Fonte: Elaboração própria

O contexto de atuação dos professores aponta majoritariamente para escolas públicas: há dois relatos sobre contexto da EI e cinco do EFI. A atuação no contexto privado é relatada em quatro artigos: um na EI e dois no EFI havendo, ainda, um relato sobre aulas particulares (\#8FRA). Quanto ao perfil dos alunos, em especial, aos níveis/anos cursados, verificamos que a maioria dos relatos trata do EFI, presente em 16 relatos que perpassam todos os anos do EFI. O ensino de espanhol e de francês localiza-se exclusivamente no quinto ano. A EI está contemplada em dez relatos que, da mesma forma que o EFI, perpassam todos os níveis da EI.

\section{OBJETIVOS DE PESQUISA}

Com relação aos objetivos, verificamos seis grandes objetivos de pesquisa. Estes têm grande variação e compreendem desde objetivos que podem ser considerados mais gerais, como contribuir para a formaçáo continuada de professores de LI, até objetivos mais específicos, como descrever e analisar um projeto de ensino. Essas ações são disponibilizadas no Quadro 3, que sintetiza essa classificação e oferece exemplos extraídos dos respectivos artigos. 
Quadro 3 - Objetivos de pesquisa

\begin{tabular}{|c|c|}
\hline OBJETIVO(S) & EXEMPLO \\
\hline Contribuir & $\begin{array}{l}\text { contribuir para a formação continuada de professores de língua inglesa [...]. } \\
\text { (\#2ING) }\end{array}$ \\
\hline \multirow{3}{*}{ Apresentar } & $\begin{array}{l}\text { apresentar as percepçóes de oito professores de Inglês do Ensino Fundamental I } \\
\text { da rede municipal [...]. (\#6ING) }\end{array}$ \\
\hline & apresentar uma sequência didática [...]. (\#8FRA) \\
\hline & $\begin{array}{l}\text { apresentar uma grade de critérios avaliativos norteadores (GCAN) [...]. } \\
(\# 4 \mathrm{ING})\end{array}$ \\
\hline \multirow{3}{*}{ Investigar } & $\begin{array}{l}\text { investigar as crenças e práticas de professores de inglês para crianças [...]. } \\
\text { (\#1ING) }\end{array}$ \\
\hline & $\begin{array}{l}\text { investigar [...] o dispositivo SD, assim como proposto por Dolz et. al (2004) } \\
\text { [...]. (\#9ING) }\end{array}$ \\
\hline & $\begin{array}{l}\text { investigar a atuação de professoras voluntárias de inglês em um Projeto de } \\
\text { Extensão [...]. (\#7ING) }\end{array}$ \\
\hline $\begin{array}{l}\text { Descrever } \\
\text { Refletir } \\
\text { Analisar }\end{array}$ & $\begin{array}{l}\text { descrever o projeto Petit e Pequeños [...]. Na sequência, trazemos a análise do } \\
\text { livro adotado, Ventanita al Espanhol } 1 \text { (Feitosa et al, 2013), com base em } \\
\text { critérios apresentados por López (2016)]. (\#5ESP) }\end{array}$ \\
\hline Discutir & $\begin{array}{l}\text { discutir a formação inicial reflexiva de professoras de inglês no projeto de } \\
\text { iniciação à docência [...]. (\#3ING) }\end{array}$ \\
\hline
\end{tabular}

Fonte: Elaboração própria

Os relatos analisados objetivam, quanto à sua contribuição, colaborar para a formação continuada de professores de LI por meio da reflexão sobre práticas em sala de aula no contexto da EI. Os objetivos que envolvem a açáo de apresentar dizem respeito 1) às percepçóes de professores de LI sobre experiências vivenciadas em formação em serviço fundamentada em perspectivas colaborativas e participativas, 2) aos princípios e elaboração de uma $\mathrm{SD}$ e 3) à uma grade de critérios avaliativos criada para orientar a avaliação e a redação de pareceres descritivos (PD) que registram e reportam o processo de desenvolvimento e a aprendizagem nas aulas de LI. Os trabalhos voltados à investigação 1) abordam crenças e práticas de professores de LI quanto à pronúncia e ao impacto da disciplina de Fonética e Fonologia da LI com uma abordagem de ensino de pronúncia nestas crenças e práticas, 2) verificam se a $S D$ pode ser utilizada como instrumento de avaliação no ensino de LAC e 3) analisam a atuaçáo de professoras de LI em um Centro de Educação Infantil, enfocando o planejamento das aulas e a utilização de material didático. A pesquisa que teve como objetivo a ação de descrever, refletir e analisar (\#5ESP), analisa criticamente o desenvolvimento do projeto Petit e Pequeños e analisa o LD Ventanita al Espanhol 1. Já aquela cujo objetivo volta-se à discussão (\#3ING), trata da formação inicial reflexiva de professoras de LI em projeto de iniciaçáo à docência 
a partir da revisão reflexiva de práticas desenvolvidas no projeto aliada à discussão teórica.

Em termos de participantes que estáo contemplados nos objetivos das pesquisas, verificamos que quatro referem-se a 1) material didático, como a produção e análise de SDs, de LD, projetos e de grade de critérios avaliativos; e que cinco referem-se a 2) professores em formaçáo inicial e continuada, e suas práticas e crenças quanto ao ensino de LI para crianças. Entendemos que os alunos integram a comunidade escolar e que são contemplados nas diversas açóes/práticas relatadas. Contudo, os mesmos não são tematizados nos objetivos de pesquisa, com exceçáo da grade de critérios avaliativos norteadores, que busca registrar o desenvolvimento e aprendizagem dos alunos.

\section{TIPO DE ESTUDO}

Todos os relatos analisados inscrevem-se no paradigma qualitativo de pesquisa. Já com relaçáo aos instrumentos explicitados, verificamos um total de quatro. $\mathrm{O}$ Quadro 4 apresenta esses instrumentos e sua localização nos respectivos artigos.

Quadro 4 - Instrumentos de pesquisa

\begin{tabular}{|c|c|}
\hline INSTRUMENTO & IDENTIFICAÇÃO DO ARTIGO \\
\hline & \#6ING \\
Entrevista & \#7ING \\
& \#2ING \\
& \#8FRA \\
\hline Grade de Critérios Avaliativos Norteadores & \#4ING \\
Ficha & \#5ESP \\
\hline Questionário & \#1ING \\
\hline Gravaçáo em vídeo & \#9ING \\
\hline
\end{tabular}

Fonte: Elaboração própria

O instrumento entrevista foi o mais utilizado, seguido da ficha e da grade de critérios. Os demais instrumentos (questionário e gravação em vídeo) foram utilizados uma vez.

Nas entrevistas conduzidas, três pesquisas investigaram a perspectiva de professores e uma apresenta dado sobre a percepção de alunos. A pesquisa (\#6ING), que investigou as percepçóes de professores sobre suas experiências formativas, propôs questóes sobre oferta de formaçóes pela Secretaria da Educação Municipal e falta de orientações oficiais para a atuação com crianças foram abordadas nas entrevistas. A pesquisa (\#7ING), que investigou aspectos da prática pedagógica de professoras de LI, contemplou perguntas como "O que você leva em consideraçáo na hora de planejar uma aula ou propor uma atividade específica?", "Como você escolhe quais materiais serão utilizados em cada aula?" e "Como você escolhe qual conteúdo vai ser aplicado?”. Na pesquisa (\#2ING), dados sobre o discurso de duas 
professoras da EI foram gerados por meio de entrevista com perguntas como: "O que a levou a atuar na EI?" e "Como você se sente ao ensinar alunos da EI?”. Já na pesquisa (\#8FRA), recorte de dissertação, que apresenta os princípios e a elaboração de uma SD em francês, a autora retoma e aponta apreciação positiva, por parte dos alunos, de atividades que envolvem manipulação.

Para a análise textual de pareceres e de LD, foram utilizados os instrumentos Grade de Critérios Avaliativos Norteadores (GCAN) e ficha, respectivamente. Na pesquisa (\#4ING), a GCAN constitui-se de 20 critérios concebidos a partir das quatro habilidades linguísticas (compreensão oral e escrita e produção oral e escrita). A ficha foi utilizada no trabalho (\#5ESP) para a análise do LD, com o objetivo de manter e disponibilizar a mesma estrutura esquematizada para qualquer analista, possibilitando a comparação de trabalhos executados por diferentes pessoas. A ficha dividiu-se em descrição interna e externa do LD, análise propriamente dita, e observações.

Questionário foi utilizado em (\#1ING). Foi dirigido a 21 professores de LI que cursavam a disciplina Fonética e Fonologia da LI e buscou gerar dados sobre suas realidades e crenças. Exemplares de perguntas utilizadas foram: "Você considera sua pronúncia em língua inglesa... (ruim, boa, muito boa e praticamente nativa)?" e "Sua pronúncia melhorou depois que você passou a ter aulas de Fonética e fonologia da língua inglesa na Especializaçáo?".

Já gravação em vídeo foi utilizada na pesquisa (\#ING9) para registrar e avaliar a produção oral em LI de alunos do quinto ano. A gravação integrou a pesquisa sobre avaliação, na qual a SD foi o instrumento avaliador da aprendizagem.

\section{RESULTADOS E IMPACTOS}

Por fim, a análise dos resultados e impactos das pesquisas relatadas apontam três grandes caracterizaçóes: 1) impactos positivos, 2) dificuldades identificadas, e 3) impactos positivos e dificuldades. O Quadro 5 sintetiza essas caracterizaçóes e apresenta exemplos a partir dos artigos do corpus. Em azul, destacamos os expoentes linguísticos relativos aos impactos positivos e, em vermelho, os relacionados às dificuldades. 


\begin{tabular}{|c|c|}
\hline $\begin{array}{l}\text { RESULTADOS/ } \\
\text { IMPACTOS }\end{array}$ & EXEMPLO \\
\hline \multirow{5}{*}{ Positivos } & $\begin{array}{l}\text { Os resultados indicaram que os informantes consideram que o ensino e o } \\
\text { estudo da pronúncia são importantes e mostrou que ainda há necessidade de } \\
\text { estudar e discutir como a pronúncia pode ser abordada nas aulas de inglês } \\
\text { para crianças. (\#1ING) }\end{array}$ \\
\hline & $\begin{array}{l}\text { Como resultado de nosso trabalho, é possível observar, além do } \\
\text { desenvolvimento linguístico, o desenvolvimento crítico dos alunos. (\#3ING) }\end{array}$ \\
\hline & $\begin{array}{l}\text { [...] encontros formativos possibilitaram uma mudança significativa na } \\
\text { formação em serviço, dando ênfase para as partilhas de experiência. (\#6ING) }\end{array}$ \\
\hline & $\begin{array}{l}\text { Podemos perceber então a dinâmica da aula e a forma como atividades } \\
\text { aparentemente desconexas podem suceder-se sem perder a coerência do todo } \\
\text { e a objetividade. O processo é possível pelo vínculo inicial que é estabelecido } \\
\text { com o tema. (\#8FRA) }\end{array}$ \\
\hline & $\begin{array}{l}\text { [...] avaliar por meio da SD diversifica os percursos do ensino aprendizagem } \\
\text { e pode [...] ser um instrumento que beneficia a diversidade individual e } \\
\text { contribui com a avaliaçáo contínua. [...] a SD é um instrumento eficaz de } \\
\text { ensino, de aprendizagem e de avaliação. (\#9ING) }\end{array}$ \\
\hline \multirow[t]{2}{*}{ Dificuldades } & $\begin{array}{l}\text { Como principais resultados, observou-se que ambas as professoras têm } \\
\text { encontrado dificuldades de caráter didático-pedagógico ao atuarem na } \\
\text { Educação Infantil e, conforme prevê a literatura vigente, ambas atribuem tais } \\
\text { dificuldades ao seu processo de formação inicial. (\#2ING) }\end{array}$ \\
\hline & $\begin{array}{l}\text { Os resultados da análise indicaram defasagem entre a concepção do material } \\
\text { e a clientela à qual ele se destina e contribuição parcial do livro didático ao } \\
\text { trabalho conduzido. (\#5ESP) }\end{array}$ \\
\hline \multirow[t]{2}{*}{$\begin{array}{l}\text { Positivos e } \\
\text { Dificuldades }\end{array}$} & $\begin{array}{l}\text { Diante dos resultados foi possível compreender melhor a atuaçáo das } \\
\text { participantes deste estudo e o que direciona suas práticas no projeto. [...]. No } \\
\text { que se refere à escolha de material, os dados gerados sugerem que as escolhas } \\
\text { foram em sua totalidade intuitivas, demonstrando, ainda, um certo receio } \\
\text { ao fazer a escolha desses materiais. [...] foi observado um engajamento das } \\
\text { participantes em promover o desenvolvimento integral das crianças [...]. } \\
\text { Nesse sentido, é possível inferir que a proposta de formaçáo das professoras } \\
\text { de acordo com a perspectiva dos multiletramentos está em consonância com } \\
\text { a prática delas [...]. (\#7ING) }\end{array}$ \\
\hline & $\begin{array}{l}\text { Foi possível verificar, por meio da análise de } 12 \mathrm{PD} \text {, que o registro da } \\
\text { aprendizagem de LIC [...], por não abordar questóes relacionadas aos } \\
\text { propósitos linguísticos, deixava a desejar no que dizia respeito aos critérios } \\
\text { avaliativos da aprendizagem de LI. [...] grade de critérios avaliativos } \\
\text { norteadores para auxiliar na redação de PD [...] pode ser um instrumento } \\
\text { eficaz no registro da aprendizagem e do desenvolvimento [...]. (\#4ING) }\end{array}$ \\
\hline
\end{tabular}

Fonte: Elaboração própria 
Verificamos que a maioria dos artigos apresenta impactos positivos referentes ao desenvolvimento das açóes propostas. Os pontos positivos dizem respeito à conscientização quanto à importância do ensino e estudo de pronúncia, bem como sua aplicaçáo em aulas de LAC (\#1ING), ao desenvolvimento do pensamento crítico e reflexivo dos alunos, além de suas habilidades linguísticas (\#3ING) e à mudança na formação de professores em serviço a partir do compartilhamento de experiências (\#6ING). Há ainda pontos positivos relativos à proposição de atividades a partir do estabelecimento de vínculo com o tema do projeto que orienta as atividades realizadas (\#8FRA) e, ainda, à SD como um instrumento amplo e eficaz, capaz de dar conta das dimensóes de ensino (diversificado), aprendizagem (significativa e contextualizada) e avaliação (contínua, do processo) (\#9ING).

As dificuldades apontadas nos relatos, por sua vez, têm caráter didáticopedagógico (\#2ING) e estão relacionadas ao planejamento e ao material didático (\#5ESP). As dificuldades didático-pedagógicas (em especial, a elaboraçáo de atividades) são atribuídas, pelas professoras que atuam na EI, à formação inicial. Os relatos chamam a atenção para a falta de disciplinas especificamente voltadas ao ensino de LI para crianças na graduação, o que compromete a atuação de futuros professores nesse contexto (\#2ING). A análise detalhada do material didático para o EFI (\#5ESP), por sua vez, aponta para a necessidade de adaptaçáo e complementação deste. Essa análise passa também pela reavaliação do público a que o material se destina, tendo em vista as necessidades e características dos alunos brasileiros.

Os relatos que apontam pontos positivos concomitantes a dificuldades apresentam, como pontos positivos, uma aproximaçáo e melhor compreensão da forma como as professoras atuam, como fazem suas escolhas, bem como indicam seu empenho em proporcionar o desenvolvimento integral dos alunos ao não limitarem suas escolhas ao ensino de itens lexicais. É ainda possível inferir que a proposta de formaçáo, embasada na perspectiva dos multiletramentos, vai ao encontro das práticas das professoras. Pode-se apontar, como dificuldade identificada, a forma intuitiva que guiou a escolha de materiais (\#7ING).

$\mathrm{O}$ registro da aprendizagem de LI foi apontado como um aspecto negativo em (\#4ING), na medida em que não endereçava propósitos linguísticos e não contemplava critérios avaliativos relativos à aprendizagem. Nesse sentido, a grade de critérios proposta constituiu-se em um impacto positivo da pesquisa, pois contribuiu para a redação dos PDs e, consequentemente, para o registro da aprendizagem.

\section{CONSIDERAÇÓES FINAIS}

Realizamos um levantamento exploratório com o objetivo de identificar relatos de pesquisa que tratassem de práticas de sala de aula no contexto da EI e/ou do EFI. A análise dos artigos indicou uma predominância da LI nas açóes voltadas ao ensino e aprendizagem de LAC. As pesquisas, em sua totalidade, inscrevem-se no paradigma qualitativo e fazem uso, em sua maioria, do instrumento entrevista para a geração de dados. As duas grandes temáticas identificadas (formação de professores de LAC e ensino das línguas inglesa, francesa e espanhola para 
crianças) demonstraram que a formação de professores, nos relatos analisados, trata exclusivamente da formação em LI. Os dados corroboram ainda a necessidade de investimento da formaçáo inicial de professores de LA de forma a contemplar o contexto da EI e do EFI. O ensino de LAC, por sua vez, contempla as demais LAs e se subdivide em práticas e avaliação do ensino. Quanto aos objetivos, resultados e impactos das pesquisas, embora tenhamos identificado uma grande variação, foi possível perceber a preocupação dos pesquisadores em intervir beneficamente junto às comunidades investigadas, perspectiva que vai ao encontro da proposta da Linguística Aplicada.

\section{REFERÊNCIAS}

CAVALCANTI, Maria do Couto. A propósito de Lingüística Aplicada. Trabalhos em Linguística Aplicada, v. 7, p. 5-12, 1986.

CIRINO, Dayane Rita de Souza; DENARDI, Didie Ana Ceni. Há espaço para o ensino de Inglês para crianças no currículo de cursos de Letras Português-Inglês? Semina:

Ciências Sociais e Humanas, v. 40, n. 2, p. 209-224, 2019.

COLOMBO, Camila Sthéfanie; CONSOLO, Douglas Altamiro. A implementação do ensino de ILEC no contexto brasileiro: percurso histórico e regulamentação políticopedagógica. In: (Orgs.). O ensino de inglês como língua estrangeira para crianças no Brasil: cenários e reflexóes. Sáo Paulo: Cultura Acadêmica, 2016. p. 53-61.

FORTE, Janaína da Silva. O Ensino de Língua Inglesa para Alunos da Educaçáo Infantil em Porto Alegre: Uma Leitura Crítica Acerca do Uso da Linguagem, do Letramento e de Crenças. Dissertação (Mestrado em Linguística Aplicada) - Universidade Federal do Rio Grande do Sul, Porto Alegre, 2010.

JORDÃO, Clarissa Menezes. ILA - ILF - ILE - ILG: quem dá conta?. Revista Brasileira de Linguística Aplicada, v. 14, n. 1, p. 13-40, 2014.

MASON, Jennifer. Qualitative researching. London; Thousand Oaks; New Delhi: Sage, 2002.

MOITA LOPES, Luiz Paulo da. Linguística aplicada e vida contemporânea: problematização dos construtos que têm orientado a pesquisa. In: (Org.). Por uma linguística aplicada INdisciplinar. São Paulo: Parábola Editorial, 2006. p. 85-107.

ROCHA, Cláudia Hilsdorf. O ensino de línguas para crianças no contexto educacional brasileiro: breves reflexões e possíveis provisōes. DELTA, v. 23, n. 2, p. 273-319, 2007.

SCAGLION, Luiz Fernando; ARAÚJO, Luciana Aparecida de; GIROTO, Cláudia Regina Mosca. Revista Entrelínguas, v. 5, n. 2, p. 359-377, 2019.

SCHLATTER, Margarete. $\mathrm{O}$ ensino de leitura em língua estrangeira na escola: uma proposta de letramento. Calidoscópio, v. 7, n. 1, p. 11-23, 2009. 
SCHLATTER, Margarete; GARCEZ, Pedro de Moraes. As línguas adicionais na formação do cidadão. In:

. (Orgs.). Línguas adicionais na escola: aprendizagens colaborativas em inglês. Erechim: Edelbra, 2012. p. 37-61.

TANACA, Jozélia Jane Corrente. Aprendizagem expansiva em espaços híbridos de formaçáo continuada de professoras de inglês para crianças no Projeto Londrina Global. 2017. 257 f. Tese (Doutorado em Estudos da Linguagem) - Universidade Estadual de Londrina, Londrina, 2017.

TONELLI, Juliana Reichert Assunção; CRISTOVÃO, Vera Lúcia Lopes. O papel dos cursos de Letras na formaçáo de professores de inglês para crianças. Calidoscópio, v. 8, n. 1, p. 65-76, 2010. 